\title{
INTEGRATING SOCIAL IMPACT MEASURES INTO THE AIRSHIP DESIGN PROCESS
}

\author{
Richards, D.C.; \\ Stevenson, Phillip D.; \\ Mattson, Christopher A.; \\ Salmon, John L. \\ Brigham Young University
}

\begin{abstract}
Engineered products have economic, environmental, and social impacts, which comprise the major dimensions of sustainability. This paper seeks to determine the interaction between design parameters when the social impacts are incorporated into the design process. Social impact evaluation is increasing in importance similar to what has happened with environmental impact consideration in recent years in the design of engineered products. Concurrently, research into new airship design has increased, however airships have yet to be reintroduced at a large scale and for a range of applications in society. Although airships have the potential for positive environmental and economic impacts, the social impacts are still rarely considered. This paper presents a case study of the hypothetical introduction of airships in the Amazon to help local farmers transport their produce to market. It explores the design space in terms of the airship's social impacts connected to the design parameters. The social impacts are found to be dependent not only on the social factors and airship design parameters, but also on the farmer-airship system, suggesting that socio-technical systems design will benefit from integrated social impact metric analysis.
\end{abstract}

Keywords: Sustainability, Conceptual design, Systems Engineering (SE), Airship, Social impact

\section{Contact:}

Richards, D.C.

Brigham Young University

Mechanical Engineering

United States of America

dc.richards@byu.edu 


\section{INTRODUCTION}

\subsection{Impacts of Product Design}

The product design process begins as requirements are defined and performance measures are established to ensure the product solves a particular problem in a desirable way (Mattson and Sorensen, 2019). Requirements are often connected, resulting in a number of tradeoffs in performance. Each of these design tradeoffs has economic, environmental, and social impacts (Mattson et al., 2019). A product's impact is an aggregation of these three factors, weighted by the design team's notion of best, and often influenced from other stakeholders or regulatory bodies.

Historically, economic impacts have been the driving force in design and business. Though more recently, awareness of social responsibility has risen through increased social connection, corporate policy, and various ISO standards (Elkington, 1998; Castka and Balzarova, 2008). Focus has also increasingly shifted toward environmental responsibility. A product's efficiency, reduced waste, and longevity are now being examined for environmental reasons in addition to how they influence a product's economic viability. These metrics are assessed from production through to the product's end-of-life to determine the product's total effect on the environment. When an existing product is updated, improvements are often incremental with each generation slightly better than its predecessor. The economic and environmental impacts are often observed and measured, then improved upon in later iterations. When a new product is designed, impacts are uncertain. Initial estimates are calculated, then improved throughout the design process.

When a new technology is introduced to the increasingly globalized world, steps should be taken to understand its impact and consequences through society on more than just an economic or environmental level. Its impact on society should also be assessed. Assessing social impact has been described as "understanding and determining the impacts on the day-to-day quality of life of persons and communities whose environment is affected by some development project" (Burdge, 1995). Social impacts are commonly framed in terms of corporate identity or consumer product development (Elkington, 1998; Rainock et al., 2018; Ottosson et al., 2020). For example, corporate initiatives for sustainability, such as the Triple Bottom Line, include a push for business practices to be sustainable through social, environmental, and economic awareness (Elkington, 1998). As the scale and complexity increase, the need for social impact consideration increases as well. As a product is adopted and reaches more people, there is a greater chance that the product will have a widespread social impact. As a product grows in complexity, the future social impact may be non-obvious and require dedicated analysis to predict the eventual impact. There has been relatively little done in social impact research for new engineered products prior to release, with most impact analysis happening postmortem or post-release. For example, in the cases of the automobile and airplane, many articles and books evaluate the past and discuss how each innovation has impacted the environment, societies, and economies throughout the world since their introduction (Womack et al., 2007; Starr, 1969). Still, by applying such efforts and knowledge to the development of future products earlier, one can aid in limiting the negative social impacts of a product's introduction. Airplanes and automobiles have allowed for an increase in the flow of people, ideas, and products throughout the world, resulting in a large impact on society. The variability in ownership, usage, and high upfront costs add additional complexity to the system that make social impacts more difficult to predict than for other products. One engineered product receiving renewed interest, and has similar potential for positive impact, with similar scale and complexity to the automobile or airplane, is the airship. Still yet to be reintroduced at a large scale, there are opportunities to design and introduce airships to positively impact society.

\subsection{Impacts of Airships}

The airship (see Figure 1), with its massive scale and potential social impact augmented by its tested but tainted history, might require consideration for social impacts to have a successful resurgence. The main reasons airships have potential large social impacts are: 1) airships can be faster than a sea cargo vessel, 2) airships are more efficient than a traditional fixed-wing or rotor aircraft, and, 3) unlike other transportation modes, airships can be mostly agnostic to landing area requirements. Thus, they are well suited to many activities in a variety of locations, with little supporting infrastructure. 


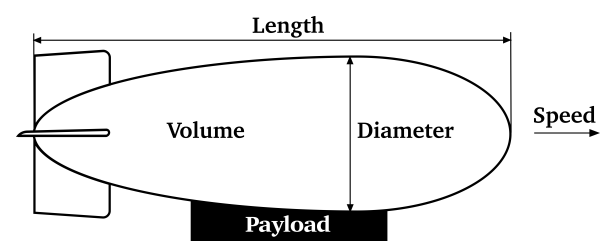

Figure 1. Diagram shows the high-level design parameters of an axisymmetric airship.

Many of the economic and environmental benefits of airships link closely to their social benefits. Since constant air displacement from rotors or forward thrust from engines is unneeded to generate lift, airships are much less noisy than helicopters or airplanes (Khoury, 2012). This means, airships can be less costly to operate, while producing less carbon emissions due to the decrease in energy use. This also decreases the discomfort of noise pollution and abates the aversion to living near an airfield. The decreased fuel consumption, combined with the ability to land virtually anywhere, makes airships an attractive transport candidate for humanitarian and disaster relief environments.

Between the 1920s and 1940s airships were used for naval surveillance, freight transportation, and even transatlantic passenger flight and flew millions of miles (Hunt, 2015). Large investment in airplane technology led to the airship being relegated to airborne advertisements and small tourist flights for the last half-century. The new millennium saw government and military organization become interested and began funding projects to develop a new generation of airships (Hunt, 2015). Then in the 2010s a number of projects began development or were transformed into more civilian-centric designs. Hybrid Air Vehicles, for example, was initially awarded a government contract for airship development and eventually reclassified their prototype as a civil aircraft (Hybrid Air Vehicles, 2020). In addition, many ideas have been proposed for airship use such as, cargo transport in the Arctic (Prentice and Thomson, 2003), humanitarian missions (Jeong et al., 2020; Tatham et al., 2017), or mobile hospitals (Paramalingam et al., 2020). With each different use case, the payload, speed, and size requirements vary. The social impacts of each use case vary as well. Consequently, social impacts cannot be measured for airships in general, but their calculation must be incorporated into the design process for each airship case. The aim of this paper is to provide a method of determining and calculating these social impacts for any airship project or of any other product of scale operating within a complex system. This addition to the design process is important both to the success of each airship design project and to the societies affected by their introduction.

This paper explains and demonstrates how to develop predictive social impact models for large, costly products that are part of socio-technical systems. Airships, with their relatively high upfront cost, shared usage and ownership, and anticipated benefit to communities, are a great candidate for this research. A case study is presented that involves the hypothetical introduction of airships into the Brazilian Amazon region to help local farmers transport and sell their produce. The foregoing example presents the key elements and challenges in incorporating social impact into the design, analysis, and implementation of these products.

\section{AIRSHIP DESIGN}

Conventional airships rely on being lighter than air. This is generally accomplished using a helium or hydrogen filled envelope. A helium-filled airship, for example, requires about one cubic meter of lifting gas for each kilogram of mass. Similar to other aircraft, the lighter the airship, its structure, engines, and other parts, the more of this lift can be used to carry cargo, people, or other useful payload. Airships often need to maintain neutral buoyancy. If they have too much buoyant lift, they will float skyward until the lifting gas envelope bursts, or until an alternative action is taken. If the airship is insufficiently buoyant, it will float to the ground or, if the ship is already on the ground, it will not be able to become airborne. Therefore, when people or cargo are unloaded, the airship either needs that weight to be replaced or the amount of lift needs to be reduced. Historically, reducing buoyancy, after a significant weight reduction at the time of payload offloading, has been accomplished by adding ballast such as sand bags or by venting the lifting gas from the airship.

Generally, airships are designed for a maximum cargo payload. This makes the neutral buoyancy difficult to maintain, particularly once the cargo has reached its final destination and has been unloaded. Recent designs, such as Lockheed Martin's LMH-1 and Hybrid Air Vehicles Airlander 10, seek to 
address the neutral buoyancy requirement in a new way. These new airships solve this problem by being slightly heavier than air and relying more on aerodynamic lift, similar to an airplane wing, to compensate for the cargo weight (Hybrid Air Vehicles, 2020; Lockheed Martin, 2020). When the cargo is dropped off, there is no need to add ballast or vent the expensive helium. This reliance on both buoyant and aerodynamic lift have led to this type called hybrid airships. One tradeoff for this hybrid solution is the airship is more reliant on airspeed and, consequently, large, open spaces for take-off and landing are required. Such tradeoffs lead to higher operating costs or decreased versatility due to a lack of runway independence when compared to conventional airships.

Operating altitude also heavily constrains airships due to their volumetric sensitivity to atmospheric pressure and temperature changes (Hunt, 2015). Airships are often flown at relatively low altitudes compared to airplanes to avoid the large volume changes experienced when rising tens of thousands of feet (Hunt, 2015). However, some projects and proposals for surveillance and observational airships are designed to float through the stratosphere, at or above 15 kilometres (Smith et al., 2011). With this requirement, a lifting gas envelope must account for the change in gas density by changing its volume as the airship rises through the atmosphere. This is achieved by carrying less payload, due to decreased lift, and by using air-filled ballonets, which are, simply, an air-filled balloon inside a larger helium-filled volume. When on the ground, the ballonets take up most of the room inside the gas envelope, but slowly release the air to make room for the expanding lifting gas as elevation increases.

Environmental conditions, in addition to payload and cruise altitude, play a large role in airship design. Consider two airships, one used near either pole and the other around the equator. An airship designed for use in the Arctic such as that proposed by Prentice and Thomson (2003) may need to be relatively larger to account for decreased lift in colder temperatures. An airship designed for the Amazon region of Brazil may need to be much smaller since it is working above a dense forest canopy with few large expanses where it can land, quite dissimilar to the arctic. Even in a similar working region, airships may have different constraints driven by their objectives.

Two recent examples of airship use in the Amazon region are for infrastructure repairs (Junior et al., 2020) and for rainforest observation (Carvalho et al., 2019). For each application, a large payload is desirable to carry enough spare parts or the necessary equipment, which would require a large airship. For the observation airship, this may not be a problem. On the other hand, the repair ship would likely need to make frequent stops at each power station or transmission line tower. This could make the airship design more dependent on the available landing locations, leading to possible size constraints. Certain areas of the Amazon forest are so dense that the only places to land in an emergency may be a small farm or a football field. While one option may be to deforest plots of land for airship landing sites, this would obviously have poor environmental and social repercussions.

Like all products, wherever airships are introduced and however airships are used, they will have an impact on society. It is then important to determine what the biggest impacts will be, maximize the positive and minimize the negative social impacts, and create metrics that tie these effects to airship design parameters such as payload or speed. In order to more systematically determine social impacts and how they affect certain design tradeoffs with product parameters and attributes, we present the following methods to help guide engineers and designers through the process.

\section{METHODOLOGY}

The methodology for social impact modeling used in this paper draws from the process introduced by Stevenson et al. (2020). The first step in this process is to determine the requirements and objectives of the product. For some products, it might also be necessary to choose one of many product use cases, since each can affect different groups of people in various ways. In order to reduce the effort associated with the social impact analysis and predictions, at least initially, a specific use case should be chosen. Once the use case of the product has been determined, those impacted by the product are identified. These people might be the product's users, people working in the same industry as the product, people living in the product's vicinity, or those funding the product's development or use. Designers should spend a thoughtful amount of time on this step as it will guide the remainder of the process.

Next, the social impacts on each group of people are described generally. One method of doing this is by using the social impact categories. In a study by Rainock et al. (2018), 11 product social impact categories were gathered from product impact studies, case studies, social impact assessments, and 
other similar studies. The social impact categories identified by Rainock et al. (2018) are: Stratification, Employment, Health, Human Rights, Networks and Communication, Conflict and Crime, Cultural Identity, Gender, Family, Population Change, Paid Work, and Education. These social impact categories have been used by other researchers to better understand and predict the social impacts of engineered products (Stevenson et al., 2020; Ottosson et al., 2020).

The third step is to select indicators for, or ways to measure, each social impact category. Indicators describe and facilitate measuring and predicting the social impacts of a product. For example, if Population Change was chosen, an indicator might be the number of people moving to and from a city. These indicators serve as the beginnings of an equation that tie a product's engineering parameters to the data that describes impacted groups and individuals. Some relevant data sources include survey data, census data, and data from the UN or World Bank. Usually such data includes demographic information (income, gender, age, occupation, etc.) on individuals within the population. Data requirements are likewise dependent on the social impact indicators. In general, the data describe the current conditions of the social impact indicators and any variables that might influence those current conditions. In determining the best indicators, it is important to begin with a wide scope to ensure the most important measures are captured. In most cases, the indicators will be reduced as a result of data limitations and desired size of the product social impact study.

After indicators are chosen, predictive models are created to quantify the social impacts. Once these models are executed, the resultant simulations are analysed for the interactions among users of the product, using data obtained about people, locale, and situation. The simulation generates intermediate variables that are ultimately combined into the social impact calculations. There are two basic equations that describe what the predictive models need. Generally, the social impact indicator is defined by:

$$
I_{S}=Y_{f}-Y_{i}
$$

where the predicted social impact of a product $\left(I_{S}\right)$ is the difference between the individual's condition prior to product introduction $\left(Y_{i}\right)$ and after the product introduction $\left(Y_{f}\right)$. Whenever possible, the initial state $\left(Y_{i}\right)$ should be a measured value. Since the social impact $\left(I_{S}\right)$ calculates the change between conditions before and after the product's introduction, the sign of this delta should be positive if an increase is desired and be negative if a decrease is desired. Therefore, it is appropriate for conditions $Y_{f}$ and $Y_{i}$ to be swapped for some impacts where a decrease is better. The basic concept for the post-introduction condition $\left(Y_{f}\right)$ is that it is a function of two sets of parameters $U$ and $P$ :

$$
Y_{f}=f(U, P)
$$

where $U$ is the set of the impacted individual's parameters and $P$ is the set of the product's engineering parameters that influence the final condition $\left(Y_{f}\right)$. A predictive social impact model needs both of these data types to be dependent on the product and sensitive to each impacted individual.

For some products, it is also necessary to create a system model. This system model should describe how people in the product-user system interact with the product and how the product influences their life. This system model will be used to calculate intermediate variables that will be used to calculate $Y_{f}$. For some products, there is often potential for considering many social impacts. The limiting factor in incorporating the social impacts of a product into the design process should be the fidelity of the social impact's predictive model. If data are not collected directly from the impacted individuals, it is likely that the fidelity of the predictive social impact models will not reach the fidelity of the models dictating the mechanical design of a product. Ultimately, the degree to which social impact models influence the engineering models for a product is decided by the product designer. When combined together, the social impact models and engineering models can assist in creating a better functioning and more impactful product design.

\section{CASE STUDY \& ANALYSIS}

\subsection{Brazil \& Farmers Background}

This example explores the potential social impacts of airships in an engineering development context. Following the process introduced in Section 3, the first step is to determine the airship's use case and impacted individuals. The chosen location for this study is the area around the city of Manaus, Brazil $\left(-3.117034^{\circ} \mathrm{S},-60.025780^{\circ} \mathrm{W}\right)$. Manaus is the capital city of the Brazilian state of Amazonas, and is the 
only free port in all of Brazil. Manaus is located in the middle of the Amazon, at the beginning of the Amazon River, a place known locally as the "meeting of the waters", see Figure 2a.

There are several reasons why airships might be an impactful and useful solution to some of the Amazon farmers' problems. Mostly, transporting goods is very difficult in the Amazon. Poor roads, variable river heights, and lack of proper transportation equipment make it difficult for smaller farmers to move their goods to markets and processing facilities (Martinot, J.F. et al., 2017). Figure $2 \mathrm{~b}$ shows the distributions of harvest times of common fruits throughout the year. The vertical lines indicate the time of the year when the river is lowest (from September to February), thus making transport by water impossible for many farmers. This time frame coincides with the harvest of many popular crops, such as lime and papaya. Naturally, when farmers are unable to transport crops and sell their product, they lose money or miss out on potential income. Airships have the potential to positively impact farmers who otherwise lose a large portion of their income and time when they unable to transport their product to a market or processing facility.

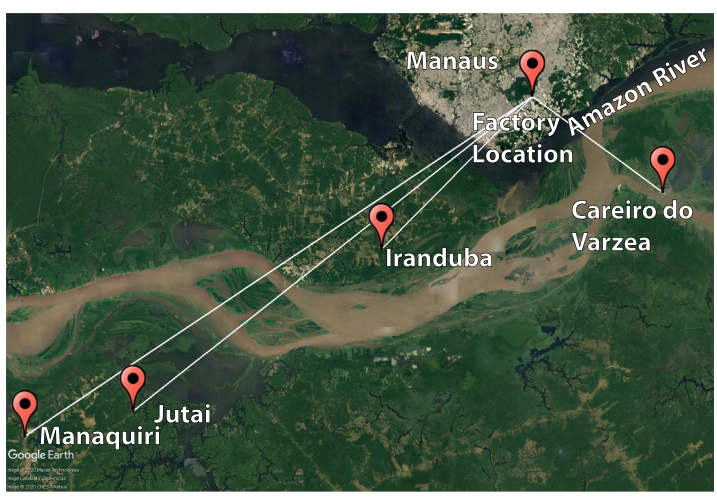

(a) Regional map around Manaus, the location of the fruit processing factory, and the cities the airship services.

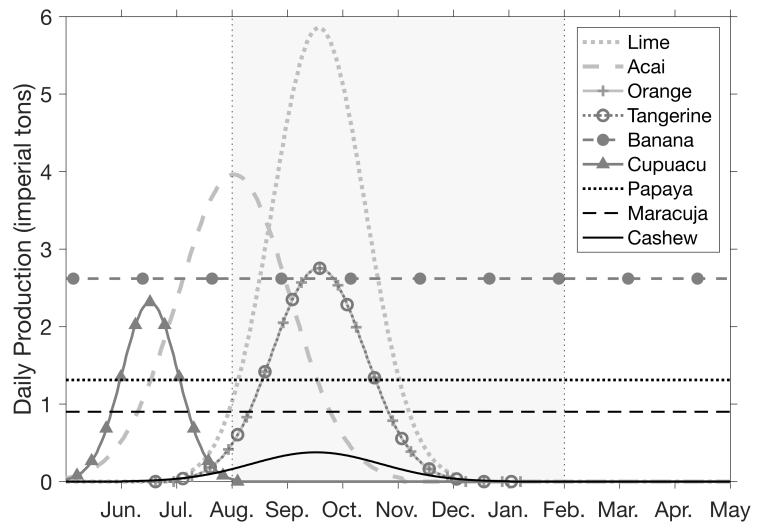

(b) Daily production over one year for the nine fruit in the four cities included in the study.

Figure 2. Regional map and fruit production numbers for the area studied.

As stated in Section 3, in order to understand the impacts of airship introduction, it is important to better understand the population of farmers who may be affected by the airship. The farmers modeled and used in this example come from four different cities: Careiro do Varzea, Iranduba, Jutai, and Manaquiri (see Table 1). Farmers' production, income, and loss data was collected from the 2017 Brazil Agriculture Census IBGE (2017). Sufficient data were extracted from this Census for 627 farmers who harvest nine different fruit crops (Figure 2b).

Table 1. Number of Farmers and distances from each city to Manaus.

\begin{tabular}{l|r|r|r} 
City & $\begin{array}{r}\text { Number of } \\
\text { Farmers }\end{array}$ & $\begin{array}{r}\text { Distance by } \\
\text { boat (miles) }\end{array}$ & $\begin{array}{r}\text { Distance by } \\
\text { Airship (miles) }\end{array}$ \\
\hline Careiro do Varzea & 102 & 13.2 & 11.0 \\
Iranduba & 314 & 25.3 & 14.7 \\
Jutai & 64 & 48.1 & 34.8 \\
Manaquiri & 147 & 59.0 & 41.8
\end{tabular}

\subsection{Engineering and Social Impact Models}

Figure 3 shows an abstraction of the high-level design and modeling process. Airship parameters are interconnected such that a main design requirement defines one of the variables which then has cascading effects to the other variables. Secondary requirements further constrain the design. In this case a certain payload necessitates a certain size of airship. But, a required cost target could reduce the possible airship size, causing the maximum payload requirement to be reduced. Social impacts $\left(I_{S}\right)$ are the change in conditions before and after airship introduction, with the post-introduction condition $\left(Y_{f}\right)$ being a function of both social constraints $(U)$ and airship parameters $(P)$, as described in Equations 
1 and 2 and the upper, right box in Figure 3. In this case, $P$ consists of any of the parameters: size, cost, payload, or speed. Each of the other rectangles shown in Figure 3 show the impacts studied in this example and which airship parameters were included in their calculations.
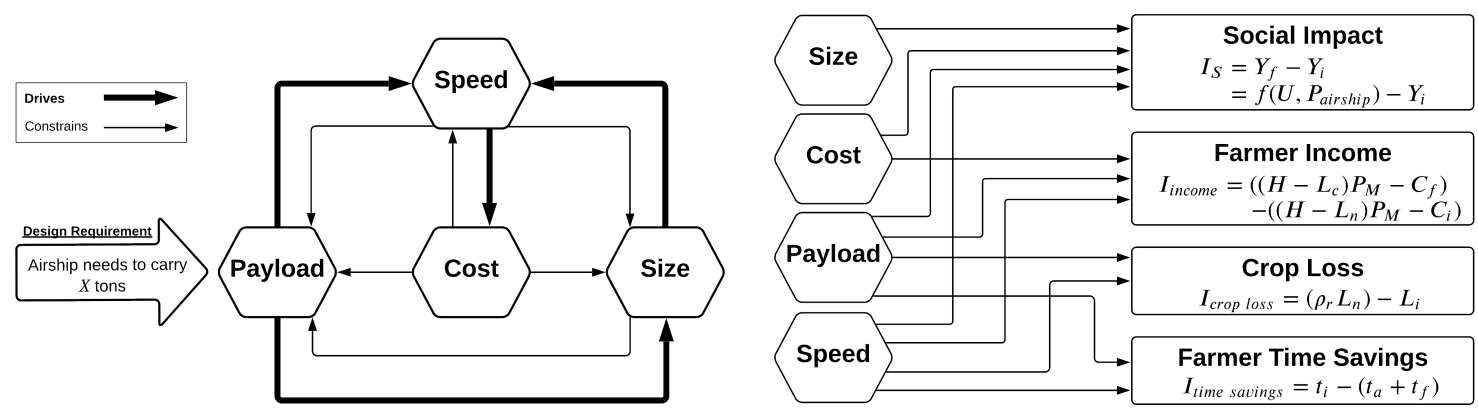

Figure 3. High-level airship design parameter interaction (left). Integration of airship design parameters and indicator variables for evaluation of the social impact metrics (right).

After following the process in Section 3, three social impacts were identified. These were impacts to farmers' time savings $\left(I_{\text {time savings }}\right)$, crop loss $\left(I_{\text {crop loss }}\right)$, and income $\left(I_{\text {income }}\right)$. The following are the equations used to calculate the social impact indicators for each of the farmers. The equation for impact to farmer time savings ( $\left.I_{\text {time savings }}\right)$ is,

$$
I_{\text {time savings }}=t_{i}-\left(t_{a}+t_{f}\right)
$$

where the initial condition $\left(t_{i}\right)$ is the time to transport a farmer's entire crop to market without an airship. The conditions after airship introduction are the time to load a farmer's crops onto the airship $\left(t_{a}\right)$ and the time to transport the goods to market that were not loaded onto the airship $\left(t_{f}\right)$. Each of these values are the total for an entire year. The calculation of $t_{a}$ is dependent on the total payload capacity of the airship and load of crops taken from a farmer's city. The calculation $t_{f}$ is dependent on airship speed and payload as the more trips the airship makes and more produce it can carry reduces the need to transport the produce another way. The equation for the impact to crop loss $\left(I_{\text {crop loss }}\right)$ is,

$$
I_{\text {crop loss }}=\left(\rho_{r} L_{n}\right)-L_{i}
$$

where $L_{n}$ is the produce loss determined from data and attributed to failing to deliver the produce to market prior to spoiling, and $\rho_{r}$ is the percentage of this loss $\left(L_{n}\right)$ that can be recouped through airship utilization. The initial condition $\left(L_{i}\right)$ is the crop loss without airship use. The term $\rho_{r}$ is dependent on the airship's ability to transport the farmers' crops, which is determined by the airship's speed and payload. If the airship's payload is large but the ship is slow it may not be able to visit each city frequently enough to gather all of the crops before losses accumulate. If the airship's payload is small but the airship is fast, it still may not be able to carry all of the farmers' crops in time. The equation for impact to farmer income $\left(I_{\text {income }}\right)$ is,

$$
I_{\text {income }}=\left(\left(H-L_{c}\right) P_{M}-C_{f}\right)-\left(\left(H-L_{n}\right) P_{M}-C_{i}\right)
$$

where $H$ is the total harvest, $L_{c}$ is the predicted crop loss when using the airship, $P_{M}$ is the market price for the crop, and $C_{f}$ is the cost to sell their crop when using the airship. $L_{n}$ is the crop loss and $C_{i}$ is the cost to sell without using the airship. As indicated by the parenthetical groupings of Equation 5, as well as the $i$ and $f$ subscripts, impact to farmer income $\left(I_{\text {income }}\right)$ is the difference of monetary states before and after airship introduction. The term $C_{f}$ is dependent on how often the farmer uses the airship, which depends on the airship's speed and payload.

\subsection{Model Assumptions}

Some assumptions were made in the creation of the models and predictions of this example. As more data are collected on the farmers and the potential farmer-airship system, some assumptions can be reduced or removed. An essential assumption deals with what data are currently available through the 2017 Brazil Agricultural Census. The data from the 2017 census does not include data on production 
numbers and sales when the subgroup of farmers is small. In this case it is assumed that the farmers from each city, on average, have similar production and sale values. Using this assumption, if a city does not have data for a crop's production or sale value, an average value from the other cities is used. Also, it is assumed that there all farmers that were included in the 2017 census. It is possible that farmers who were not already selling their products are not included in the data. If this is the case, the total impact of an airship might be increased from additional farmers using the airship.

Secondly, it is assumed that each farmer behaves similarly. In this example, it is assumed that the farmers would sell as much of their produce as possible to the factory using the airship. This assumption is based on the potential of the farmers to reduce their crop loss to zero as the airship has the potential to transport all of their products on a daily or weekly basis. Similarly, it is assumed that the product they are unable to sell to the factory, they would sell at the same rate they currently sell based on the 2017 census. It is also assumed that the farmers all sell their product at the markets in Manaus.

\section{RESULTS \& DISCUSSION}

The results of the above social impact modeling show how the social impact of an airship is correlated with the airship design parameters. Figure 4 shows the results of the simulation and social impact calculations. The social impacts change as functions of the airship's payload and speed parameters. Each of the three impacts are the difference between conditions from a prior state without airships and the state after airship introduction. To determine the total impact for each, and how they relate to airship parameters, values from data (IBGE, 2017) and the intermediate, calculated values from numerous simulations were incorporated into Equations 3-5. The simulations spanned the design space defined by an airship payload of zero to 15 imperial tons $(13608 \mathrm{~kg})$ and an airship speed of zero to 50 knots $(92.6 \mathrm{~km} / \mathrm{h})$. A zero payload and a zero airspeed model the state of no airship introduction and the resulting social impact is zero.

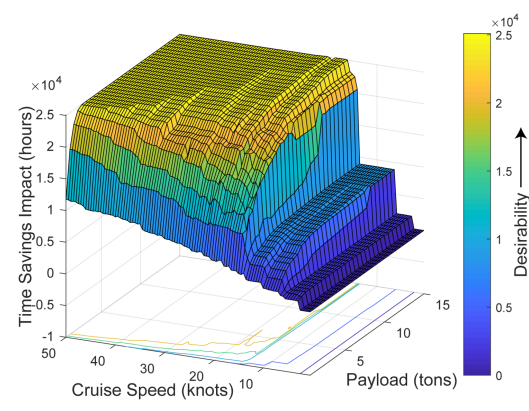

(a)

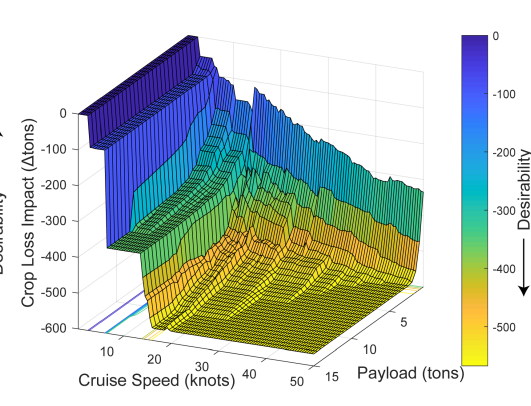

(b)

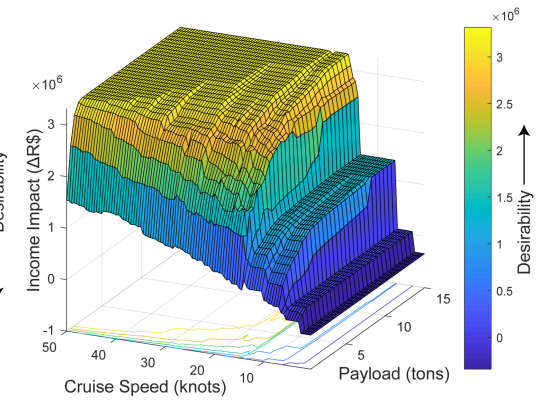

(c)

Figure 4. Social impact indicators, totaled for all farmers in all cities, are plotted against the linked airship design parameters. The Z-Axes show the social impacts. The color scale provides an indication of social impact improvement, with the arrow indicating the direction of desirability (corresponding to increasingly lighter colors). Note that the $X$ - and $Y$-Axes show payload and speed, with axes reversed for impacts where a negative impact is desirable.

These results show that in order to produce the greatest social impact, the airship's speed and payload both need to be increased, to a point. If airship speed is increased without increasing payload and vice versa, then the social impact will never reach the maximum potential impact. Despite this interrelationship between payload and speed, the social impact from increasing either depends on the location in the design space. Once all of the cities can be reached by the airship, increasing speed does not increase the social impact as much as increasing payload can. Similarly, if all of the cities can not be reached by the airship, then increasing payload will not greatly effect the social impact of the airship. By exploring the results, an airship can be designed that has the best possible social impacts across a set of designs, similar to a Pareto-frontier. Thus, the maximum social impacts can be seen in Figures $4 \mathrm{a}-4 \mathrm{c}$ as the plateaued area. In order to improve the social impact of an airship with design parameters in the plateaued area, other various system-level parameters would need to change. For example, the farmers can produce more crops, grow different crops, send products to other locations, or the airship can visit more cities or areas with farmers. 
Going through the process to determine the social impact of the airship, we found that the social impact of the airship is highly dependent on the airship-farmer system as well as the airship's engineering parameters. Figures $4 a-4 c$ each have discontinuous jumps in how much of a change in time savings, crop loss, and income the farmers can anticipate. These jumps occur when the airship is able to travel to a new city. When a city's distance becomes reachable within a workday's travel distance, the airship visiting new cities can increase social impact dramatically. Looking at Figure 4b, there are four jumps in crop loss when the cities of Careiro do Varzea, Iranduba, Jutai, and Manaquiri are accessible to the airship in a daily round trip, determined by the airship's speed.

\section{CONCLUSION AND FUTURE WORK}

Through the proposed methods and case study of airship fruit transport in Brazil, we have shown how social impact metrics can be calculated for large-scale products operating within socio-technical systems. We found that by varying airship parameters, it is possible to explore the design space and determine optimal designs in the context of social impact. Through this process, the importance of the system and operational models on the social impacts became clear. The decisions of farmers and the ways in which the airship was used can have a large influence on the social impacts. This provides the opportunity for further research into the design space of social impacts and engineering parameters. As well as how agent-based modeling and the integration of variable operational and logistic parameters can provide further resolution into the calculation of social impact metrics.

Additional research and refinements to this initial study would generate other findings that could help airship designers and decision makers maximize the positive social benefit to the area. For example, the surfaces in Figure 4 show the interaction of the product's sustainability space (Mattson et al., 2019) and design space. Applying this linked space, designers could visualize, explore, and better understand the direct interactions between engineering parameters and social impacts. Further investigations into how this sustainability-design space could be leveraged to further predict related designs and products' impacts on society.

What's more, this model only analysed airships with useful payloads up to 15 imperial tons (13608 $\mathrm{kg}$ ) and a hub and spoke route between Manaus and each city of farmers. Given different operational parameters and an airship with a larger payload, the effects to social impact may change considerably. In Figure 4 the impact plateau is reached when the amount of produce no longer fills the airship for each trip. In this case an airship may need to visit additional cities prior to returning to Manaus. This would impact fuel consumption and the number of trips the airship could make in one day, resulting in more cities and more farmers that could be reached. Further analysis could compare these different logistics models. This analysis would require a more detailed cost model than used in this study. Varying the logistical parameters would require more direct comparisons of speed and fuel consumption, and the initial costs for different sized airships. This comparison would determine the optimal combination of airship design for given logistics methods, likely weighing the variations of upfront and operational costs for different numbers and sizes of airships. These interactions may lead to increased social impact metrics that remove or raise the level of the impact plateau in Figure 4.

Another tradeoff not analyzed in this model is airship size, e.g. length, width, or volume. Although size is driven mainly by the desired payload, none of the social impacts modeled were constrained by size directly. Since this simulation took place in the Amazon forest, size could be limited by available landing area. A 20-ton-carrying airship may be the largest feasible airship for the area if the largest available landing sites are the size of a football pitch. The density and rapid growth of the vegetation in the Amazon make it difficult to clear land. Even if the land is cleared, the forest continually tries to reclaim the land, making it difficult to maintain. As a result, an airship size constraint is likely. This is assuming that the airship must land to be used. Alternatively, operational parameters might change and the produce could be loaded into a container that has been lowered from the airship via a winch system, allowing for an oversized airship. Adjusting operational parameters like this will be important for future studies and would necessitate additional adjustments to the social impact evaluation models.

The variation of operational and logistic parameters if integrated into the social impact model could provide further insight into the effects they have on the model and resulting social impact metrics. It may also provide insight on how changes to how the airship is used may provide increased benefit compared to the initial plans for operation. 


\section{REFERENCES}

Burdge, R.J. (1995), A Community Guide to Social Impact Assessment, Social Ecology Press.

Carvalho, J.R.H., Rueda, M.Á.C., Azinheira, J.R., Moutinho, A., Mirisola, L.G.B., de Paiva, E.C., Nogueira, L.A.C.O., et al. (2019), "System Architecture of a Robotics Airship", Available at: https://doi.org/10.1007/978-3-030-55374-6_2.

Castka, P. and Balzarova, M.A. (2008), "ISO 26000 and supply chains - On the diffusion of the social responsibility standard", International Journal of Production Economics, Vol. 111 No. 2, Available at: https://doi.org/10.1016/j.ijpe.2006.10.017.

Elkington, J. (1998), "Partnerships from cannibals with forks: The triple bottom line of 21 st-century business", Environmental Quality Management, Vol. 8 No. 1, pp. 37-51.

Hunt, P. (2015), Advanced Airship Technologies and Design Approaches, edited by Hunt, P. V., American Institute of Aeronautics and Astronautics, Inc., Reston, VA, Available at: https://doi.org/10.2514/4.103520.

Hybrid Air Vehicles. (2020), Airlander 10. [online] Hybrid Air Vehicles, Available at: https://www.hybridairvehicles.com/about-us/our-history// (accessed November 2020).

IBGE_-Instituto Brasileiro de Geografia e Estatística. (2017), Censo Agropecuário de 2017, Rio de Janeiro, 775 p. Available at: https://sidra.ibge.gov.br/pesquisa/censo-agropecuario/censo-agropecuario-2017 (accessed November 2020).

Jeong, H.Y., Yu, D.J., Min, B.-C. and Lee, S. (2020), “The humanitarian flying warehouse”, Transportation Research Part E: Logistics and Transportation Review, Vol. 136, Available at: https://doi.org/10.1016/j.tre.2020.101901.

Junior, W.C., Felippes, M.A. and de Souza Bronzeado, H. (2020), “A novel environmental friendly approach to enhance the maintenance and construction of high voltage transmission lines in the Amazon region", 2020 IEEE EEEIC / I\&CPS Europe, IEEE, Available at: https://doi.org/10.1109/EEEIC/ICPSEurope49358.2020.9160562.

Khoury, G.A. (2012), Airship Technology, edited by Khoury, G., 2nd Edition., Cambridge.

Lockheed Martin. (2020), Hybrid Airship. [online] Lockheed Martin, Available at: https://www.lockheedmartin.com/en-us/products/hybrid-airship.html (accessed November 2020).

Martinot, J. F., Pereira, H. dos S., and Silva, S. C. P. da. (2017). Coletar ou Cultivar: as escolhas dos produtores de açaí-da-mata (Euterpe precatoria) do Amazonas. Revista de Economia e Sociologia Rural, 55(4), 751-766.

Mattson, C.A., Pack, A.T., Lofthouse, V. and Bhamra, T. (2019), "Using a Product's Sustainability Space as a Design Exploration Tool”, Design Science, Vol. 5, Available at: https://doi.org/10.1017/dsj.2018.6.

Mattson, C.A., and Sorensen, C.D. (2019). Product Development: Principles and Tools for Creating Desirable and Transferable Designs. Springer Nature.

Ottosson, H.J., Mattson, C.A. and Dahlin, E.C. (2020), “Analysis of Perceived Social Impacts of Existing Products Designed for the Developing World, With Implications for New Product Development", Journal of Mechanical Design, Vol. 142 No. 5, Available at: https://doi.org/10.1115/1.4044323.

Paramalingam, R., England, R., Mollura, D. and Koff, D. (2020), "Expanding the reach of global health radiology via the world's first medical hybrid airship: A SWOT analysis", Journal of Global Health, University of Edinburgh, Vol. 10 No. 1, Available at:https://doi.org/10.7189/JOGH.10.010374.

Prentice, B. and Thomson, J.T. (2003), "Airship Applications in the Arctic: Preliminary Economic Assessment", AIAA's 3rd Annual Aviation Technology, Integration, and Operations (ATIO) Forum, American Institute of Aeronautics and Astronautics, Reston, Virigina, Available at: https://doi.org/10.2514/6.2003-6847.

Rainock, M., Everett, D., Pack, A., Dahlin, E.C. and Mattson, C.A. (2018), “The social impacts of products: a review”, Impact Assessment and Project Appraisal, Taylor and Francis Ltd., Vol. 36 No. 3, pp. 230-241.

Smith, I., Lee, M., Fortneberry, M. and Judy, R. (2011), "HiSentinel80: Flight of a High Altitude Airship", 11th AIAA Aviation Technology, Integration, and Operations (ATIO) Conference, American Institute of Aeronautics and Astronautics, Reston, Virigina, Available at: https://doi.org/10.2514/6.2011-6973.

Starr, C. (1969), "Social Benefit versus Technological Risk", Science, American Association for the Advancement of Science, Vol. 165 No. 3899, pp. 1232-1238.

Stevenson, P.D., Mattson, C.A. and Dahlin, E.C. (2020), “A Method for Creating Product Social Impact Models of Engineered Products", Journal of Mechanical Design, Vol. 142 No. 4, Available at: https://doi.org/10.1115/1.4044161.

Tatham, P., Neal, C. and Wu, Y. (2017), “Hybrid cargo airships: a humanitarian logistic game changer?”, Journal of Humanitarian Logistics and Supply Chain Management, Emerald Group Publishing Ltd., Vol. 7 No. 2 , pp. 102-125.

Womack, J.P., Jones, D.T. and Roos, D. (2007), The Machine That Changed the World: The Story of Lean Production-Toyota's Secret Weapon in the Global Car Wars That Is Now Revolutionizing World Industry, Simon and Schuster. 